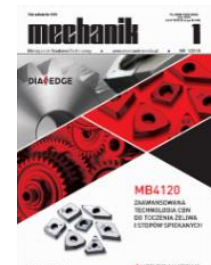

How to cite this article:

Authors: . Przemysław Poszwa, Paweł Brzęk, Wiktor Hoffmann

Title of article: "Spontaneous buckling of thin-walled injection-molded parts"

Mechanik, No. 1 (2019)

DOI: https://doi.org/10.17814/mechanik.2019.1.1

\title{
Spontaneous buckling of thin-walled injection-molded parts
}

\author{
PRZEMYSŁAW POSZWA \\ PAWEL BRZĘK \\ WIKTOR HOFFMANN *
}

Mgr inż. Przemysław Poszwa, przemyslaw.b.poszwa@doctorate.put.poznan.pl- Instytut Technologii Materiałów Politechniki Poznańskiej, Polska mgr inż. Paweł Brzęk, pawel.brzek@put.poznan.pl - Instytut Technologii Materiałów Politechniki Poznańskiej, Polska

mgr inż. Wiktor Hoffmann, wiktor.j.hoffmann@doctorate.put.poznan.pl - Katedra Techniki Cieplnej Politechniki Poznańskiej, Polska

Injection molding technology has a wide range of industrial applications, especially in packaging and casing production. In this paper the spontaneous buckling of thin-walled injection molded plastic parts was described. Theoretical background along with numerical simulation and experimental validation of this phenomenon were presented.

KEYWORDS: injection molding, buckling, warpage

\section{Introduction}

Plastics have a favorable ratio of elasticity to density modulus, due to which they have found wide application in many industries. Injection molding technology also allows to obtain parts with complex shapes and thin walls in one operation, in a very short time.

A major disadvantage of plastics is the anisotropic contraction that occurs during solidification during the injection process. It results in many problems at the production implementation stage, because in the case of complex shapes it is very difficult to predict the values of contraction in individual directions and thus the size and form of deformation. It is only the use of advanced simulation programs that can accurately predict the effect of anisotropic contraction, which is the final shape of the compact [1].

The contraction effect is not the only source of problems when designing the molded parts. In addition, residual stress frozen in the molding after processing [2] is a very important aspect. They can affect the strength of the compact and can cause an effect rarely considered at the design and simulation stage - namely, the phenomenon of spontaneous buckling of the compact. It is observed only in thin-walled moldings, however, it can cause significant problems in maintaining their flatness [3, 4].

This paper discusses the causes and pattern of residual stress formation and their relationship to spontaneous buckling of compacts. These considerations are illustrated by numerical simulations of postinjection molding of molds, the results of which were compared with the effect of the experiment.

\section{Variation in the volume of plastic as a function of pressure and temperature}

The direct causes of anisotropic contraction are low thermal conductivity of polymers, viscoelasticity and large non-linear volume variation depending on temperature and pressure.

Plastics are characterized by variable specific volume $V$ depending on the conditions (pressure in the injection mold $P$, temperature of the material $T$ after injection into the mold). The $V$ dependence on other parameters is different for materials with partly crystalline and amorphous structure. The graph of the $P-V-T$ relationship for partially crystalline material (Moplen HP500N isotactic polypropylene) is presented in fig. 1, and for amorphous one (Makrolon 2405 polycarbonate), in fig. 2.

Depending on the location of the injection point, type of the gate and adjustable parameters, the plastic in a given place compacts at different pressure values inside the injection mold. 


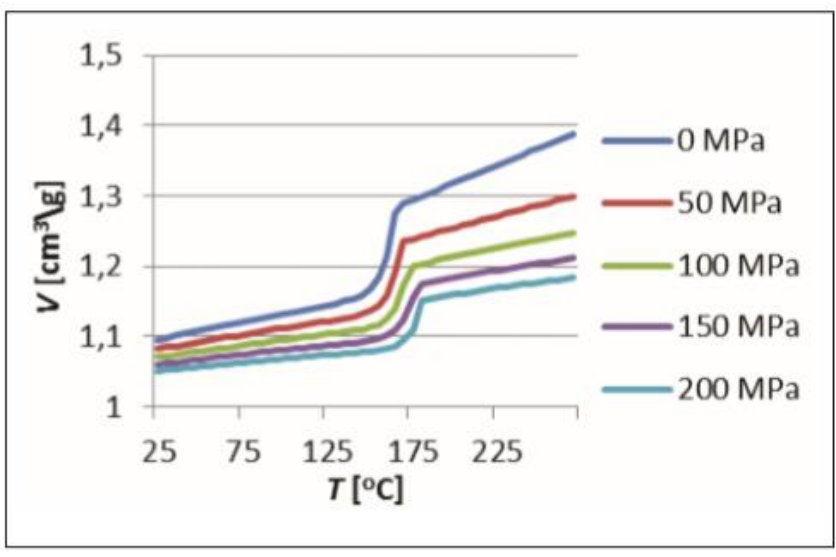

Fig. 1. $P$ - $V$-T relationship for Moplen HP500N [5]

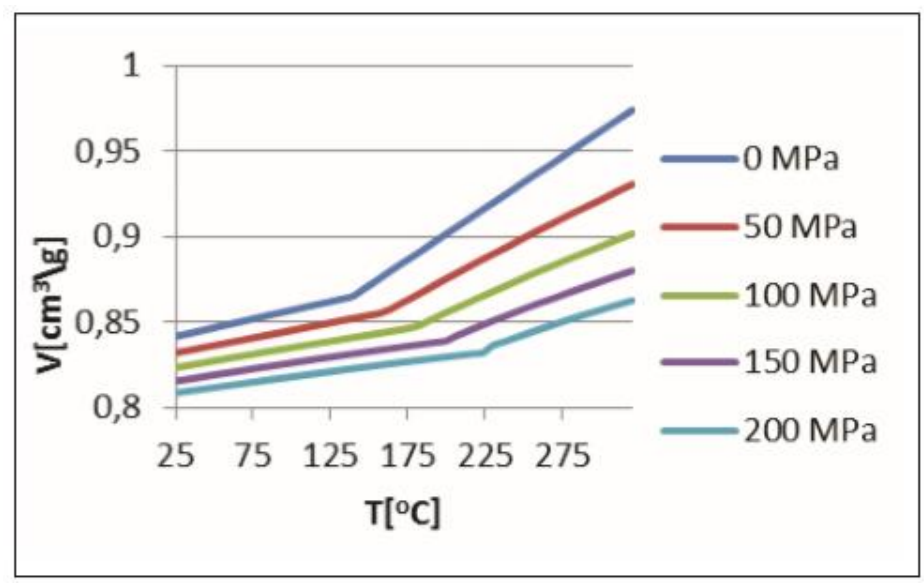

Fig. 2. P-V-T relationship for Makrolon 2405 [6]

Fig. 3 shows the pressure value, at which a given compacted area of the plastic solidified. This directly affects the formation of thermally induced residual stresses.

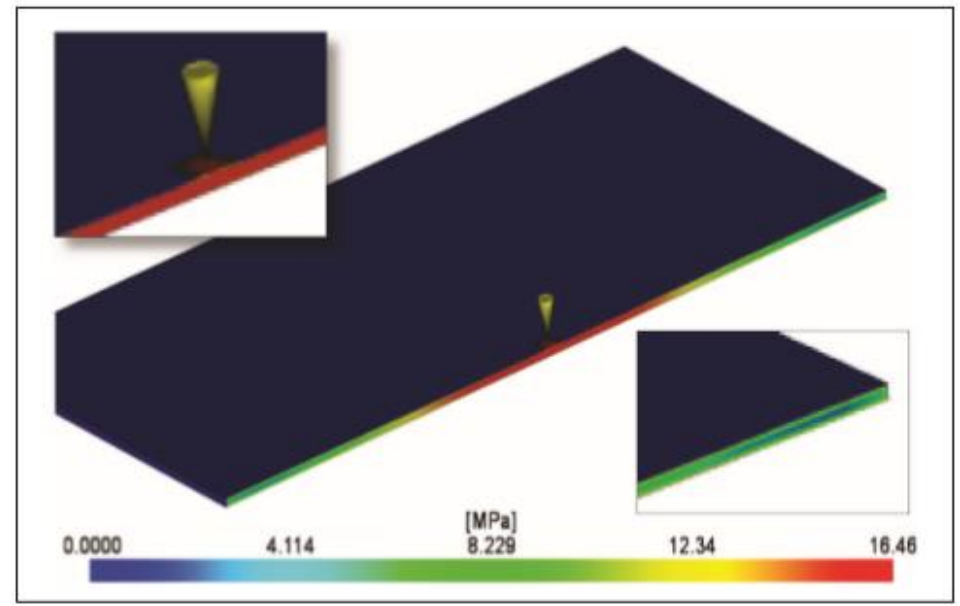

Fig. 3. Pressure distribution in the sample, at which a given compacted area solidifies (cross-section)

Basically, flow-induced and thermal residual stresses are distinguished (in unfilled materials, the former are usually omitted, because they are an order of magnitude lower than the latter). The formation of thermal residual stresses can be divided into five stages, shown in fig. 4 . 


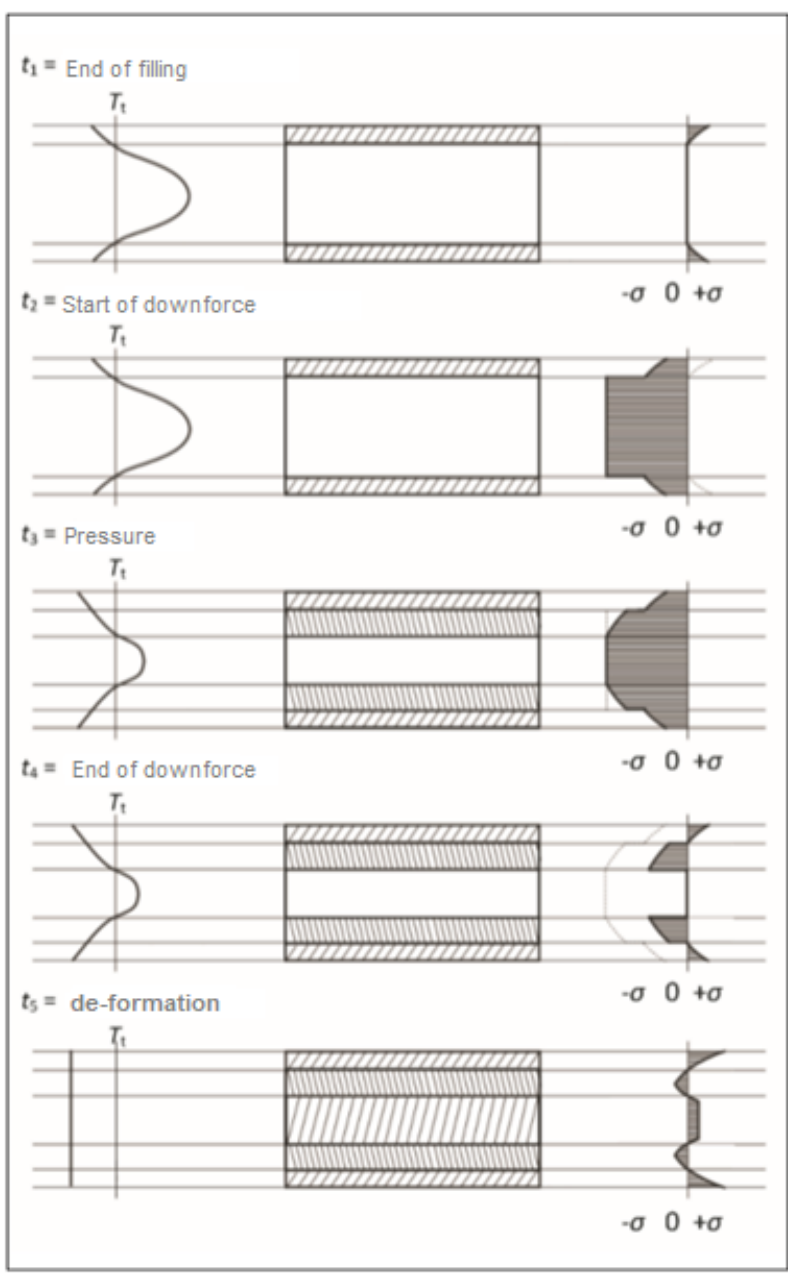

Fig. 4. Process of thermally induced residual stress formation [7]

On the left, the temperature distribution in the center of the solidified layer is shown, and on the right, the stress distribution in the individual freezing stages of the compact, i.e.:

- $t=t_{0}$ - in the entire volume, there is an even temperature and no stress;

- $t=t_{1}$ - at zero pressure, the compacted surface layer solidifies, the volume of which is smaller than the volume of the liquid material; tensile stress of low value occurs;

- $t=t_{2}$ - downforce pressure $p h$ is applied that causes compressive stresses. In liquid material, they are equal to $\sigma=-p_{h}$, and in solidified top layer $\Delta \sigma=v p_{h} /(1-v)$, where $v$ is the Poisson number;

- $t=t_{3}$ - the pressure is constant, a certain layer of plastic solidifies, its contraction is limited by the pressure in the socket (figs. 1 and 2), which reduces compressive stresses;

- $t=t_{4}$ - the pressing phase is over, the downforce pressure is equal to 0 , stresses are shifted by $\Delta \sigma$;

- $t=t_{5}$ - the detail is removed from the mold, further cooling causes tensile stresses, because in the absence of pressure, the process proceeds as during the free cooling [7].

During the last phase, tensile stresses are built to balance the compressive stresses. Due to the predominance of compressive stresses, consideration should be given to the possibility of buckling phenomena in the case of thin-walled moldings.

\section{Buckling phenomenon}

The buckling phenomenon found in thin-walled constructions is related to the bifurcation theory. If the element is loaded with compressive forces, its shortening is observed. When the applied forces are significant, it may turn out that instead of shortening in the tested element, its off-axis bending will occur.

Below a certain amount of load (so-called critical force), there is only one possible form of deformation. Above this value, it appears that two equivalent forms of deformation arise (bifurcation occurs), while the pure compression form is unstable.

An example of such a phenomenon is an axially compressed ruler, which under a load of a certain value tends to bend into an arc [8]. 
Because it does not matter whether the state of stress occurring in the tested element is the result of external forces or "frozen" residual stresses, the phenomenon of stability loss (buckling or warping) can occur spontaneously (without external forces) in the compact after it has been removed from the mold. The presented description of the buckling phenomenon shows that it concerns thin-walled structures. This means that this phenomenon will only occur in the case of thin-walled moldings.

\section{Description of the experiment}

In the Autodesk Moldflow Insight 2018 program, simulation tests were performed along with validation in the form of an experiment, illustrating the phenomenon of spontaneous buckling of thin-walled plastic moldings. The validation was carried out on an Engel ES 90/20 HLS injection molding machine. A $1.2 \mathrm{~mm}$ thick compact with $100 \mathrm{~mm} \times 100 \mathrm{~mm}$ dimensions was tested (in the case of the injection mold, an aluminum insert was used to reduce the thickness of the seat from $4 \mathrm{~mm}$ to the assumed thickness). The injection process was carried out for Moplen HP500N isotactic polypropylene with the following adjustable parameters:

- injection speed: $42 \mathrm{~cm}^{3} / \mathrm{s}$,

- pressing time: $0.5 \mathrm{~s}$,

- maximum injection pressure: 1800 bar,

- pressing pressure: 300 bar,

- material temperature: $220^{\circ} \mathrm{C}$,

- mold temperature: $35^{\circ} \mathrm{C}$,

- cooling time: $2 \mathrm{~s}$.

The injection mold was cooled by a symmetrically arranged U-shaped system with $50 \mathrm{~mm}$ channel spacing and $10 \mathrm{~mm}$ channel diameter (water temperature $20^{\circ} \mathrm{C}$ ). The cooling channels were moved away from the socket by $16.25 \mathrm{~mm}$ (mold moving plate) and $14 \mathrm{~mm}$ (mold fixed plate), respectively. In the case of numerical simulations, ideal heat collection from the mold was assumed at a constant temperature of $25^{\circ} \mathrm{C}$.

\section{Results}

The simulations included analysis of compact deformation taking into account the theory of small and large deformations (in the case of the theory of small deformations in this case, it is impossible to predict the form of buckling of the compact).

Fig. 5 shows deformation of the compact in terms of small deformations, where only contraction of the compact in the plane can be observed. It can be completely compensated by scaling the forming cavity by $0.66 \%$. After such scaling, deformation of the compact is less than $0.03 \mathrm{~mm}$. Fig. 6 , in turn, shows the form of deformation, which takes into account the possibility of buckling.

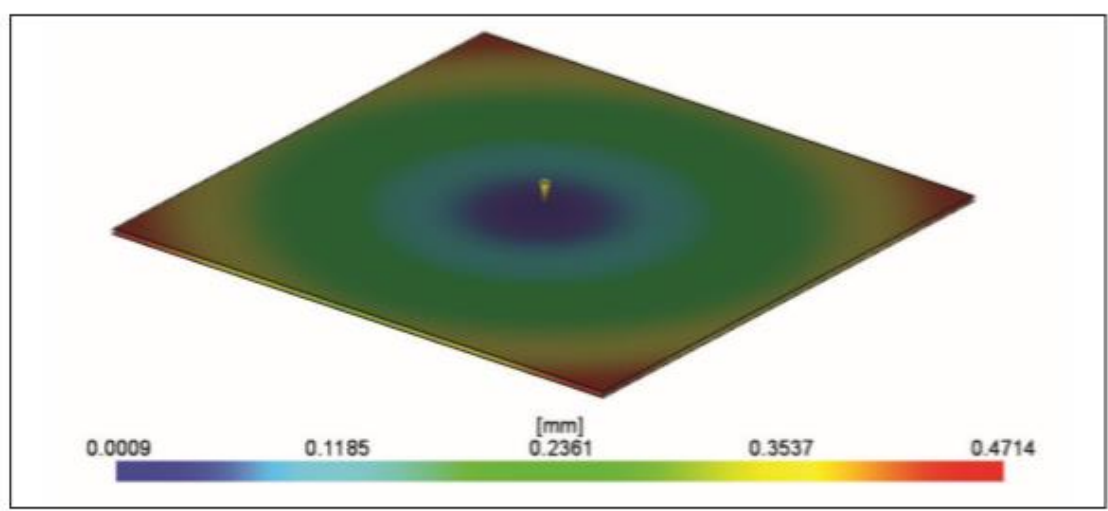

Fig. 5. Mold deformation determined using the theory of small deformations. Off-plane deformation at the level of numerical error 


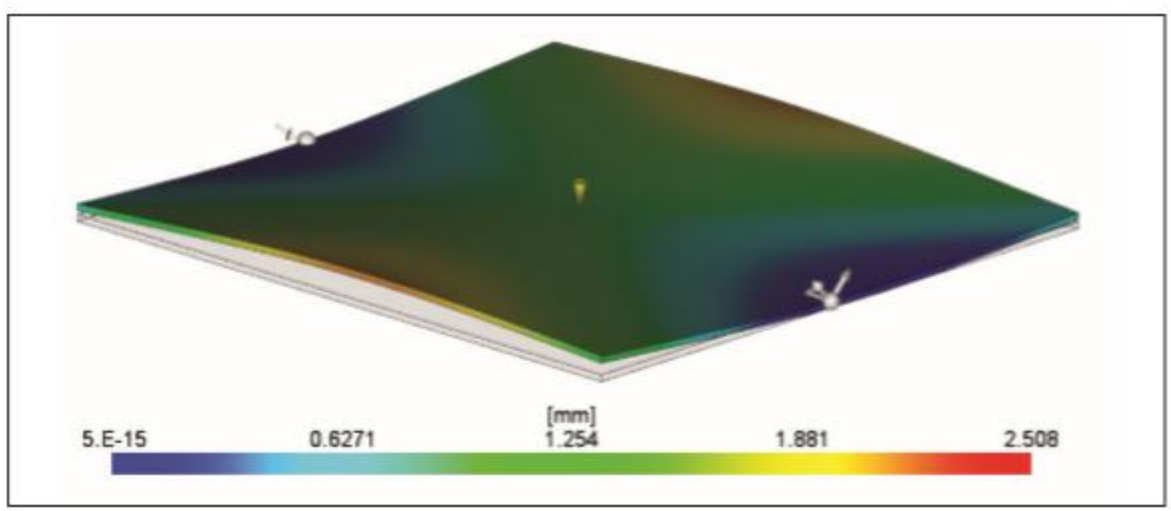

Fig. 6. Mold deformation determined using large deformation theory. The amount of deformation in the drawing has been scaled (scale factor $=2$ )

As it can be seen, for the given thickness of the compact, the maximum off-plane deflection is about $2.5 \mathrm{~mm}$. For validation, the injection process was carried out with the same presetting parameters. The form of spontaneous buckling of the actual compact is shown in fig. 7. The maximum deflection was measured, which was about $3.9 \mathrm{~mm}$.

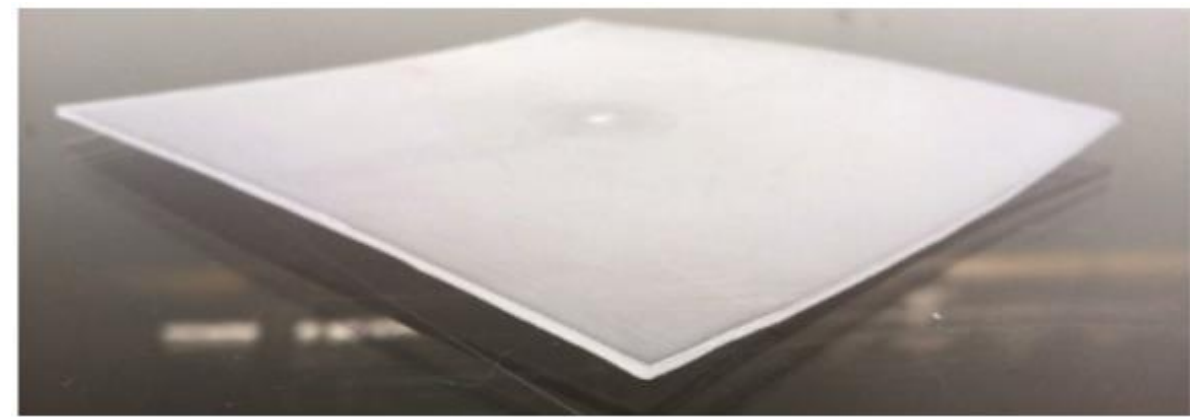

Fig. 7. Deformation of the actual compact obtained as part of the injection process

Experimental studies have allowed to observe the phenomenon of spontaneous buckling. Injected moldings had the same form of deformation as in the case of simulation, but the value of deformation was higher which results from the use of an aluminum insert mold reducing the thickness of molding, which caused unsymmetrical heat reception (higher thermal conductivity than in the case of steel). Asymmetrical heat reception was the source of an additional disturbance reducing the stability of the compact (in buckling issues, these are 'imperfections'). Confirmation of the buckling effect was obtaining in experimental studies on two equivalent buckling forms (due to the symmetry of the compact), i.e. the sample took both forms, which can be obtained by rotating the compact by $90^{\circ}$ (this was found on the basis of traces left by the surface of the forming socket).

\section{Summary}

In this work, residual stress in molded parts obtained by plastic injection method is associated with the buckling of thin-walled elements.

The phenomenon of spontaneous buckling of thin-walled moldings is an effect usually overlooked in the case of plastics moldings, often mistakenly associated with problems related to inhomogeneous cooling (inhomogeneous cooling can intensify this effect as an imperfection reducing the stability of the element).

This effect can cause a lot of trouble, because compacts that should be flat in conventional deformation analysis are not. This can be avoided by optimizing the adjustable parameters of the injection process and by changing the geometry of the compact: increasing the rigidity of the compact by both changing its geometry (adding ribs) and increasing the wall thickness. 


\section{REFERENCES}

[1] Poszwa P., Szostak M. „Symulacja deformacji wyprasek z uwzględnieniem utwierdzenia wynikającego z montażu". Mechanik. 12 (2017): 1190-1192.

[2] Zawistowski H., Frenkler D. „Konstrukcja form wtryskowych do tworzyw termoplastycznych”. Warszawa: Wydawnictwo Poradników i Książek Technicznych, 2003.

[3] Fan Z., Yu H., Xu J., Astbury D. „Buckling prediction in 3D warpage simulation of injection molded plastics". ANTEC 2013: 71 th Annual Technical Conference of the Society of Plastics Engineers, 2013.

[4] Fan Z., Astbury D., Wang H., Friedl C. "Geometric nonlinearity in 3D warpage simulation of injection molded plastics". ANTEC 2011: 69 th Annual Technical Conference of the Society of Plastics Engineers, 2011.

[5] Wang J. "PVT Properties of polymers for injection molding". Some Critical Issues for Injection Molding. InTech, 2012.

[6] Autodesk Inc. Autodesk Moldflow Insight, San Rafael, CA. 94903, USA, 2017.

[7] Guevara-Morales A., Figueroa-Lopez U. "Residual stresses in injection molded products". Journal of Material Science. 49, 13 (2014): 4399-4415.

[8] Bloom F., Coffin D. "Handbook of Thin Plate Buckling and Postbuckling". London: Chapman and Hall/CRC, 2000. 